\title{
Cytotoxicity Assay of 2,4-Dihydroxide-4'-Methoxychalcone Against Cervical (HeLa) Cancer Cell by MTT Assay
}

\author{
Novia Suryani ${ }^{1}$, Sabirin Matsjeh², Mutmainah ${ }^{3}$, Daratu Eviana Kusuma Putri' ${ }^{4}$, Damayanti Iskandar ${ }^{5}$, \\ Syarifah Asyura ${ }^{6}$ \\ ${ }^{1}$ Universitas Islam Negeri Mataram, West Nusa Tenggara, Indonesia \\ ${ }^{2}$ Universitas Gadjah Mada, Yogyakarta, Indonesia \\ ${ }^{3}$ Hokkaido University, Kita 21 Nishi 11, Sapporo 001-0021, Japan \\ ${ }^{4}$ Univesitas Negeri Malang, East Java, Indonesia \\ ${ }^{5}$ Universitas Raden Fatah, Palembang, South Sumatera, Indonesia \\ ${ }^{6}$ Universitas U'budiyah Indonesia, Aceh, Indonesia
}

Corresponding author: noviasuryani@uinmataram.ac.id

\begin{abstract}
Chalcone is one of the phenolic group secondary metabolic with numerous biological activities. Many studies have shown that chalcone derivatives compound has anti-cancer, anti-inflammatory, antimalarial, and antibacterial activities. The purpose of this research was to study the prediction potency $\alpha, \beta$ unsaturated carbonyl system of chalcone derivative against HeLa cell by MTT assay. Those activities assumed can inhibit the mechanism action of NF-kB that caused cervical cancer. The 2,4-dihydroxide-4'methoxychalcone has done synthesis as a target compound by a sonochemical for 7 hours. The results showed that chalcone derivative most active against the HeLa cell.
\end{abstract}

Keywords: active site; anticancer compound; cervical cancer; chalcone derivative;

\section{Introduction}

Cancer is a disease caused by abnormal and uncontrolled cell growth (Anwar et al., 2018). In its development, cancer cells can spread to other parts of the body and end in death. In general, the cause of cancer cannot be ascertained. Various factors both genetic and environmental factors (Shanmugam et al., 2016) have a certain contribution to increasing the risk of cancer. Various types of cancer, including breast cancer and cervical cancer, are contributors to sufficient mortality, tragically, cervical cancer is one of the most cancer that diagnosed among woman (Bak et al., 2016), however, new drug and new technologies or all-combined have been allowed as solve a problem (Bedell et al., 2020).

Treatment efforts in terms of dealing with cancer certainly continue. Given the predicted increase in the surge in cancer patients by 300 percent worldwide in 2030 with a quantity of 70 percent in developing countries including Indonesia. Based on the Ministry of Health data, the prevalence of cancer can reach 4.3 to 1,000 people. For 2020 , about 13,800 new cases of cervical cancer diagnosed in women between 35 until 44 ages year old and 4,290 women die caused cervical cancer based on The American Cancer Society's estimates. Chalcone as flavonoids classes of plant-derived compounds containing than 4000 secondary metabolites (Syed et al., 2016) which several biological effects, in recent years, have biochemical and pharmacological as well as anti-cancer 
(Alper et al., 2019). Flavonoids as a natural product such as oxorylin A, wogoni, and vitexin were reported for the treatment of cancer diseases and undergoing phase I/II clinical trials in China (Liu et al., 2020). The conjugation, hydroxylation, and substitutions in the chemical structure of chalcone derivates may give significant biological activities and flavonoids classes were bearing hydroxyl group and double bond of ring recently designed synthesized as biochemical properties as against cancer (Hoang et al., 2015).

Various treatments for many types of cancer, chemotherapy surgery, radiotherapy, or combinations, however, multidrug resistance happens in some cases. The development of another new drug for design and discovery needs to solve the problem (Abbas et al., 2019). Chalcone is an important anti-cancer agent that discovery in the synthesized drug-using mechanism of cytotoxic activity of chalcone included by apoptosis, cell cycle disruption, inhibition of tubulin polymerization, blockade of nuclear factor-kappa B and inhibition of kinases for cervical cancer cell (Abbas et al., 2019). Nuclear factor-kappa B (NF-kB) one of the transcription factors as a molecular target that critical factors and important studies intervention biological, pharmacological and development new drug since they involved in the control of immune responses that causes cancer diseases (Kaneko et al., 2019).

The aim of the study was to predicted and investigate of the compound that obtained by hydroxyl and $\alpha, \beta$ unsaturated carbonyl system in chemical structure in term of anti-cancer by blockade nuclear factor-kappa B (NF- $k$ B) that the first classical pathway (Escárcega et al., 2007) induced genes. This general structure of synthesized is shown in Figure 1. and cytotoxic properties shown by the MTT assay data as a cytotoxic assay that used directly (Abel \& Baird, 2018) to determine cell viability.

\section{Material and Method}

The procedure of synthesis of 2,4-dihydroxide-4'-methoxychalcone using the sonochemical method for 7 hours in (Suryani et al., 2019), and all chemicals used purified by column chromatography to yield product and purchased commercially. 2,4dihydroxide-4'-methoxychalcone characterized by FT-IR, GC-MS, ${ }^{1} \mathrm{H}$, and ${ }^{13} \mathrm{C}-\mathrm{NMR}$.

In Vitro anti-cancer, HeLa cells (Luong et al., 2017) (human cervical cancer) in this research were culture in Roswell Park Memorial Institute (RPMI) from Parasitology Laboratory, Universitas Gadjah Mada. The procedure was started in RPMI, $100 \mathrm{~mL}$ of cell suspension containing 106 cells was added into microplate 96 each well and incubated for $24 \mathrm{~h}$ at $37{ }^{\circ} \mathrm{C}$ and $5 \% \mathrm{CO}_{2}$. A test chalcone compound solution was inserted into a cell suspension that had been incubated previously. Added $100 \mathrm{~mL}$ of RPMI and cancer cells in wells as media and cell control. After the incubation, the culture media was removed and washed by PBS, then MTT solution of $100 \mathrm{~mL}$ (9.5 mL of RPMI and 1 $\mathrm{mL}$ of MTT solution) was inserted into wells and incubated again for $4 \mathrm{~h}$ with the same condition. $100 \mathrm{~mL}$ of $10 \%$ SDS in $0,1 \mathrm{~N} \mathrm{HCl}$ as stopper reaction added into each of wells. 
Next, the wells left at room temperature overnight were wrapped by paper tightly. Then, absorbance reading by ELISA reader at $595 \mathrm{~nm}$ (wavelength optimum) and Percentage of survival cells were determined and calculated by eq. 1 .

$\%$ cell $=\frac{(a-b)}{(c-b)} \times 100 \%$

where,

$\mathrm{a}=$ absorbances of samples

$\mathrm{b}=$ absorbances of controls media

$\mathrm{c}=$ absorbances of controls cell

\section{Result and Discussion}

\subsection{Result}

The compound of 2,4-dihydroxide-4'-methoxychalcone has been synthesized by (Suryani et al., 2019) with yield product $98 \%$, respectively. Sonochemical method using to achieve optimal yield and this method an alternative to a short time reaction of synthesis. Methanol as a solvent (Figure 1) for synthesis growth a yield as good as possible and evaporated easily. The result showed that the sonochemical method was efficient (Monsef et al., 2020) since the conventional method needs a long time reaction for 24-72 hours.<smiles>CC(=O)c1cc(O)cc(O)c1</smiles>

1<smiles>COc1ccc(C=O)cc1</smiles>

2<smiles>COc1ccc(/C=C/C(=O)c2cc(O)cc(O)c2)cc1</smiles>

3

Figure 1. General one-pot synthesis method with reagents; 1) acetophenone, 2) benzaldehyde and product; 3) 2,4-dihydroxide-4'-methoxychalcone

Chalcone compound was identified by spectral data IR, EI-MS, ${ }^{1} \mathrm{H}$, and ${ }^{13} \mathrm{C}-\mathrm{NMR}$ (Suryani et al., 2019). By ${ }^{1} \mathrm{H}-\mathrm{NMR}, \mathrm{H} \alpha$ with 7,44 ppm and $\mathrm{H} \beta$ 7,86 ppm with doublet peak $U=15 \mathrm{~Hz}$ ) described the $\alpha, \beta$ unsaturated carbonyl of chalcone were performed. That peak with chemical shift was specific for $\alpha, \beta$ unsaturated carbonyl of chalcone. Furthermore the chemical shift of $\mathrm{H} \beta$ presenced downfield since resonance by electronwithdrawing side with $\mathrm{H} \beta$.

Hence we assumed that activity in vitro of chalcone against a panel of human cervical cell lines (HeLa) by applying 3-(4,5-dimethylthiazol-2-yl)2,5-diphenyl tetrazolium bromide (MTT) assay as the most popular assessment of viability and cytotoxicity (Pascua-Maestro et al., 2018). Chalcone has an active compound as 
inhibition of cell growth with $\mathrm{IC}_{50}$ value less than $20 \mu \mathrm{g} / \mathrm{mL}$, moderate active with $\mathrm{IC}_{50}$ value $20-100 \mu \mathrm{g} / \mathrm{mL}$ and not active in the inhibition of cell growth if IC $_{50}$ value than 100 $\mu \mathrm{g} / \mathrm{mL}$ (Anwar et al., 2018). Based on $\mathrm{IC}_{50}$ references, chalcone synthesized has moderate activity with $\mathrm{IC}_{50}$ (percentage at which $50 \%$ of HeLa cells are dead) value shown in Table 1, but that activity of the compound is not selective because of that activity against normal cell (Vero) by $42,29 \mu \mathrm{g} / \mathrm{mL}$ with the low selectivity index 0,57 .

TABLE 1. IC 50 values and selectivity index of chalcone

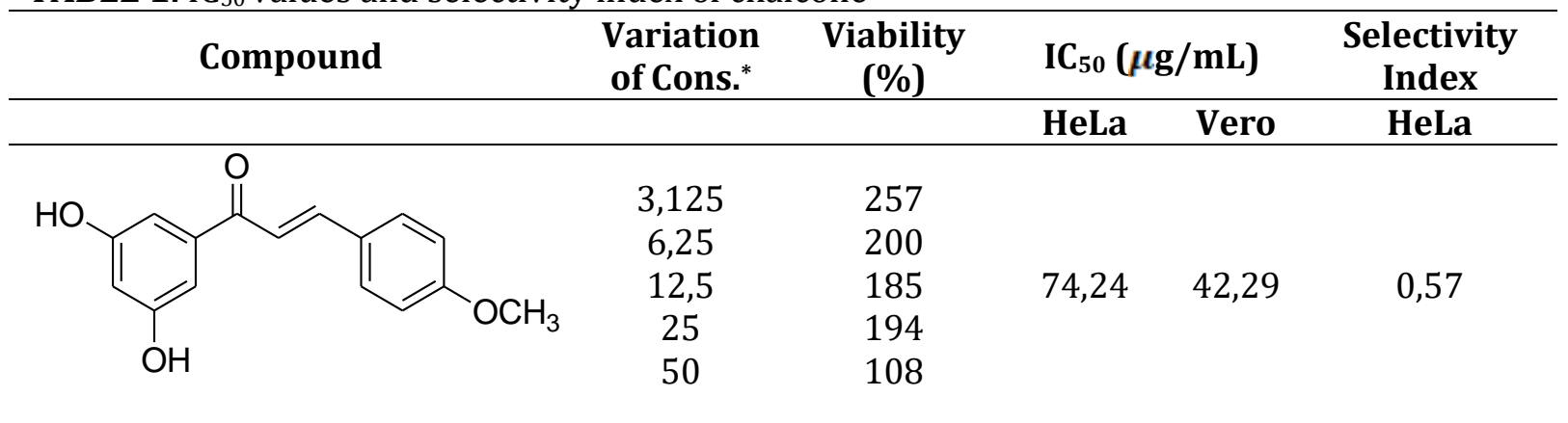

${ }^{*}$ Concentration in $\mu \mathrm{g} / \mathrm{mL}$

\subsection{Discussion}

Chalcone compound, 2,4-dihydroxide-4'-methoxychalcone was prepared by the Claisen-Schmidt according to Scheme 1. To obtain chalcone in good yield, the residues were treated with $10 \%$ in methanol. The synthesis compound was evaluated for its activity as anti-cancer by showed IC $_{50}$ value may be influenced to such factors like the nature of substitutions in the ring of chalcone, the genetic and biochemical specific compound (Solomon \& Lee, 2012).

Based on Table 1, it showed that the IC $\mathrm{I}_{50}$ value chalcone derivative is $74,24 \mathrm{~g} / \mathrm{mL}$ with $0,57 \mathrm{~g} / \mathrm{mL}$ of selectivity index. The $\mathrm{IC}_{50}$ value calculated, represents that the concentration of the result in a $50 \%$ decrease in cell growth since the chalcone compound is the most widely known as anti-cancer agents. The range as moderate activity, the chalcone compound showed as generally better against HeLa cell lines cancer. The addition of the hydroxyl group at positions 2 and 4 in ring A may affect the activity cancel line inhibitor, also the methoxy group presence increases inhibitory activity too.

As a whole, chalcone structure consists of two aromatic rings (A and B) (Han et al., 2019) with disubstituted of a hydroxyl group in ring A and monosubstituted of methoxy in ring B (Mahapatra et al., 2015) have activities moderate level since that substituted important as active site (Venkateswararao et al., 2012). Moreover, it was also has a double bond opening ring of benzene. Accordingly, the chalcone compound should undergo mechanism investigation to understand the active sites as potentially more drug agents. Nuclear factor- $k \mathrm{~B}(\mathrm{NF}-k \mathrm{~B})$ one of a key role in cancer disease (Folmer et al., 
2008), then as a subunit of the transcription factor in cancer cells, NF- $k \mathrm{~B}$, controlled immune responses, proliferation, apoptosis and tumorigenesis (Wu et al., 2019).

Investigated of chalcone, particularly that hydroxyl group in the aromatic ring did not give a significant activity (Zhang et al., 2018), but $\alpha, \beta$ unsaturated carbonyl of chalcone predicted inhibiting the activity of transcription activity in an uncontrolled cell (Bazzaro et al., 2011) than it may represent at Figure 2.

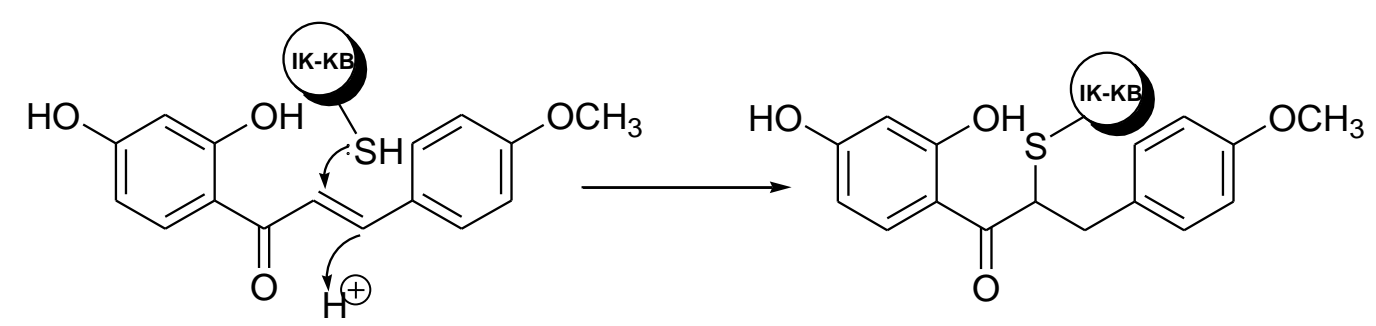

Figure 2. Predicted interaction $\alpha, \beta$ unsaturated carbonyl by I $k-k \mathrm{~B}$ at NF- $k \mathrm{~B}$ transcription

From Scheme 2, $\alpha, \beta$ unsaturated carbonyl of chalcone attacked by $\mathrm{I} k-k \mathrm{~B}$, that it was IKK protein-mediated of the NF- $k$ B activation pathway (Yadav et al., 2011). Based on the mechanism reaction of Scheme 2, bonding between protein $\mathrm{I} k-k \mathrm{~B}$ and $\alpha, \beta$ unsaturated carbonyl of chalcone may stop NF- $k$ B pathway as caused proliferation of cancer cells in humans. As a candidate drug, a mechanism the activity chalcone assumed by blocked the NF-kB pathway was identified since the in-vitro MTT assay test.

In other particularly research, the hydroxyl group of chalcone as flavonoid metabolic secondary, interaction too with $\mathrm{I} k-k \mathrm{~B}$ of human and it useful to synthesis a novel drug (Moulishankar \& Lakshmanan, 2020). When we treat cancer cases, activation of NF- $k \mathrm{~B}$ should be blocked and the $\mathrm{I} k-k \mathrm{~B}$ activation pathway did not bind with NF- $k \mathrm{~B}$ when $\alpha, \beta$ unsaturated carbonyl bind with I $k-k \mathrm{~B}$ than NF- $k \mathrm{~B}$ transcription factor will be inhibited (Yoon \& Rui, 2007). Despite chalcone effects, it potency (Meng et al., 2014), the active site for inhibited NF- $k$ B was an important role in determining chalcone to docking molecular as an anti-cancer drug in future (Ren et al., 2017). To rapidly, when the compound of drug identify inhibiting the NF- $k$ B signaling pathway currently these drugs provide have development.

\section{Conclusion}

Briefly, Chalcone derivative was synthesized successfully by the sonochemical method, and presence yields $98 \%$ with $\mathrm{IC}_{50}$ value $74,24 \mathrm{~g} / \mathrm{mL}$. The biological activity was studied, from data can be seen that the $\mathrm{IC}_{50}$ value of chalcone has a moderate activity towards cervical (HeLa) cancer cell lines. According to the $\mathrm{IC}_{50}$ and selectivity index value, it can be indicated that chalcone derivative against a cervical cancer cell line may affect since $\alpha, \beta$ unsaturated carbonyl of chalcone and that assumed as the active sites for inhibiting growth cancer line by binding with $\mathrm{I} k-k \mathrm{~B}$ protein then blocked NF- $k \mathrm{~B}$ 
pathway activation as caused cancer growth. This suggests that chalcone derivative is a potential for studies as a new anti-cancer candidate drug

\section{References}

Abbas, Samar H., El Hafeez, Amer Ali Abd., Shoman, Mai E., Montano, Monica, M., \& Hassan, Heba A. (2019). New Quinoline/Chalcone Hybrids as Anti-Cancer Agents: Design, Synthesis, and Evaluations of Cytotoxicity and PI3K Inhibitory Activity. Bioorganic Chemistry, 82, 360-77. https://doi.org/10.1016/j.bioorg.2018.10.064

Abel, Sean D.A. \& Baird, Sarah K. (2018). Honey Is Cytotoxic towards Prostate Cancer Cells but Interacts with the MTT Reagent: Considerations for the Choice of Cell Viability Assay. Food Chemistry, 241, 70-78. https://doi.org/10.1016/j.foodchem.2017.08.083.

Alper, Pınar., Erkisa, Merve., Genckal, Hasene, Mutlu., Sahin, Saliha., Ulukaya, Engin., \& Ari, Ferda. (2019). Synthesis, Characterization, Anticancer and Antioxidant Activity of New Nickel(II) and Copper(II) Flavonoid Complexes. Journal of Molecular Structure, 1196: 783-92. https://doi.org/10.1016/j.molstruc.2019.07.009

Anwar, Chairil., Prasetyo, Yogo, Dwi., \& Matsjeh, Sabirin. (2018). Synthesis of Chalcone Derivatives and Their in Vitro Anticancer Test against Breast ( T47D ) and Colon (WiDr) Cancer Cell Line. Indonesia. J. Chem, 18 (1): 102-107. https://doi.org/10.22146/ijc.26864

Bak, Min, Ji., Gupta, Soumyasri, Das., Wahler, Joseph., \& Suh, Nanjoo. (2016). Role of Dietary Bioactive Natural Products in Estrogen Receptor-Positive Breast Cancer." Seminars in Cancer Biology, 40-41, 170-191. https://doi.org/10.1016/j.semcancer.2016.03.001

Bazzaro, Martina, Anchoori, Ravi K., Mudiam, Mohana Krishna R., Issaenko, Olga., Srinivas Kumar, Karanam, Balasubramanyam., Lin, Zhenhua., Vogel, R, I., Gavioli, R., Destro, F., Ferreti, V., Roden, R, B, S., \& Khan, Saeed, K. (2011). $\alpha$, $\beta$-Unsaturated Carbonyl System of Chalcone-Based Derivatives Is Responsible for Broad Inhibition of Proteasomal Activity and Preferential Killing of Human Papilloma Virus (HPV) Positive Cervical Cancer Cells. Journal of Medicinal Chemistry, 54 (2), 449-456. https://doi.org/10.1021/jm100589p

Bedell, Sarah L., Goldstein, Lena, S., Goldstein, Amelia, R., \& Goldstein, Andrew T., (2020). Cervical Cancer Screening: Past, Present, and Future. Sexual Medicine Reviews 8 (1), 28-37. https://doi.org/10.1016/j.sxmr.2019.09.005

Escárcega, R. O., Fuentes-Alexandro, S., García-Carrasco, M., Gatica, A., \& Zamora, A. (2007). The Transcription Factor Nuclear Factor-Kappa B and Cancer. Clinical Oncology 19 (2), 154-161. https://doi.org/10.1016/j.clon.2006.11.013 
Folmer, Florence., Harrison, William, T, A., Tabudravu, Jioji, N., Jaspars, Marcel., Aalbersberg, William., Feussner, Klaus., Wright, Anthony D., Dicato, Mario., \& Diederich, Marc. (2008). NF-KB-Inhibiting Naphthopyrones from the Fijian Echinoderm Comanthus Parvicirrus. Journal of Natural Products 71 (1): 106-111. https://doi.org/10.1021/np070290y

Han, Xue, Peng, Bin., Li Cao, Bei-Bei, Xiao, S., Yang, Chao-Rui., Wang, Wen-Zhu, Wang, FuCheng., Li, Hong-Yun., Yuan, Xiao-Li., Shi, Ruifeng., Liao, Ji., Wang, Hailong., Li, Jing., \& Xu, Xingzhi. (2019). Synthesis and Evaluation of Chalcone Analogues Containing a 4-Oxoquinazolin-2-Yl Group as Potential Anti-Tumor Agents. European Journal of Medicinal Chemistry, 162, 586-601. https://doi.org/10.1016/j.ejmech.2018.11.034

Hoang, T, Kim-Dung, Huynh, T, Kim Chi., \& Nguyen, Thanh-Danh. (2015). Synthesis, Characterization, Anti-Inflammatory and Anti-Proliferative Activity against MCF-7 Cells of 0-Alkyl and 0-Acyl Flavonoid Derivatives. Bioorganic Chemistry, 63, 45-52. https://doi.org/10.1016/j.bioorg.2015.09.005

Kaneko, Tomoatsu, Zaw, Su, Yee, Myo., Sueyama, Yukiko., Katsube, Ken ichi., Kaneko, Reika., Nör, Jacques, E., \& Okiji, Takashi. (2019). Inhibition of Nuclear Factor Kappa B Prevents the Development of Experimental Periapical Lesions. Journal of Endodontics, 45 (2), 168-73. https://doi.org/10.1016/j.joen.2018.10.006

Liu, Renbo, Deng, Xiangping., Peng, Yijiao., Feng, Wanshi., Xiong, Runde., \& Zou, Yang. (2020). Bioorganic Chemistry Synthesis and Biological Evaluation of Novel 5, 6, 7Trimethoxy Flavonoid Salicylate Derivatives as Potential Anti-Tumor Agents." Bioorganic Chemistry, 96, 0045-2068. https://doi.org/10.1016/ j.bioorg.2020.103652

Luong, Duy., Kesharwani, Prashant., Alsaab, Hashem O., Sau, Samaresh., Padhye, Subhash., Sarkar, Fazlul H., \& Iyer, Arun, K. (2017). Folic Acid Conjugated Polymeric Micelles Loaded with a Curcumin Difluorinated Analog for Targeting Cervical and Ovarian Cancers. Colloids and Surfaces B: Biointerfaces, 157, 490-502. https://doi.org/10.1016/j.colsurfb.2017.06.025

Mahapatra, Kar, Debarshi., Bharti, Sanjay, Kumar., \& Asati, Vivek. (2015). Anti-Cancer Chalcones: Structural and Molecular Target Perspectives. European Journal of Medicinal Chemistry 98, 69-114. https://doi.org/10.1016/j.ejmech.2015.05.004

Meng, Ying., Zhang, Hongwei., Liu, Zehua., Zeng, Shanchao., Zhang, Hongwei., Sun, Chiyu., Zhang, Lijuan., Zhao, Ming ming., Wang, Guan., Jiang, Mengying., Shi, Wei., \& Song, Hongrui. (2014). Design, Synthesis and Antitumor Activity of PyrrolopyrazinoneChalcone Hybrids. Chemical Research in Chinese Universities, 30 (4), 624-31. https://doi.org/10.1007/s40242-014-3542-z 
Monsef, Rozita., Ghiyasiyan-Arani, Maryam., Amiri, Omid., \& Salavati-Niasari, Masoud. (2020). Sonochemical Synthesis, Characterization and Application of PrVO4 Nanostructures as an Effective Photocatalyst for Discoloration of Organic Dye Contaminants in Wastewater. Ultrasonics Sonochemistry, 61, 104822 https://doi.org/10.1016/j.ultsonch.2019.104822

Moulishankar, Anguraj., \& Lakshmanan, Karthikeyan. (2020). Data on Molecular Docking of Naturally Occurring Flavonoids with Biologically Important Targets. Data in Brief, 29, 105243. https://doi.org/10.1016/j.dib.2020.105243

Pascua-Maestro, Raquel., Corraliza-Gomez, Miriam., Diez-Hermano, Sergio., PerezSegurado, Candido., Ganfornina, María, D., \& Sanchez, Diego. (2018). The MTTFormazan Assay: Complementary Technical Approaches and in Vivo Validation in Drosophila Larvae. Acta Histochemica, 120 (3), 179-186. https://doi.org/10.1016/j.acthis.2018.01.006

Ren, Bing zhao., Ablise, Mourboul., Yang, Xu-chao., Liao, Bo er., \& Yang , Zheng. (2017). Synthesis and Biological Evaluation of $\alpha$-Methyl-Chalcone for Anti-Cervical Cancer Activity. Medicinal Chemistry Research 26 (9), 1871-83. https://doi.org/10.1007/s00044-017-1891-0

Shanmugam, Muthu K., Lee, Jong Hyun., Chai, Edna Zhi Pei., Kanchi, Madhu, Mathi., Kar, Shreya., Arfuso, Frank., Dharmarajan, Arunasalam., Kumar, A, P., Ramar, Perumal, Samy., Looi, Chung, Yeng, Mustafa, Mohamad, Rais., Tergaonkar, Vinay., Bishayee, Anupam., Ahn, Kwang Seong., \& Sethi, Gautam. (2016). Cancer Prevention and Therapy through the Modulation of Transcription Factors by Bioactive Natural Compounds. Seminars in Cancer Biology 40-41: 35-47. https://doi.org/10.1016/j.semcancer.2016.03.005

Solomon, V. Raja., \& Lee, Hoyun. (2012). Anti-Breast Cancer Activity of Heteroaryl Chalcone Derivatives. Biomedicine and Pharmacotherapy 66 (3), 213-220. https://doi.org/10.1016/j.biopha.2011.11.013

Suryani, Novia., Matsjeh, Sabirin., \& Swasono, Respati, Tri. (2019). Synthesis and Heme Polymerization Inhibitory Activity (HPIA) Assay of Chalcone, Flavone and Flavanone Derivatives Flavone, Material Science forum, 948, 109-114. https://doi.org/10.4028/www.scientific.net/MSF.948.109

Syed, Deeba N., Adhami, Vaqar, Mustafa., Khan, Naghma., Khan, Mohammad Imran., \& Mukhtar, Hasan. (2016). Exploring the Molecular Targets of Dietary Flavonoid Fisetin in Cancer. Seminars in Cancer Biology, 40-41, 130-40. https://doi.org/10.1016/j.semcancer.2016.04.003

Venkateswararao, Eeda, Sharma, Vinay, K., Lee, Ki-Cheul, Sharma, Niti., Park, Sun-Hong., Kim, Youngsoo., \& Jung, Sang-Hun. (2012). A SAR Study on a Series of Synthetic Lipophilic Chalcones as Inhibitor of Transcription Factor NF-KB. European Journal of Medicinal Chemistry, 54, 379-86. https://doi.org/10.1016/j.ejmech.2012.05.019 
Wu, Ke-Jia, Liu, Xie., Wong, Suk-Yu., Zhou, Yuyang., Ma, Dik-Lung., \& Leung, Chung-Hang. (2019). Synthesis and Evaluation of Dibenzothiophene Analogues as Pin1 Inhibitors for Cervical Cancer Therapy. Research-article. ACS Omega, 4 (5), 9228-34. https://doi.org/10.1021/acsomega.9b00281

Yadav, Vivek R., Prasad, Sahdeo., Sung, Bokyung., \& Aggarwal, Bharat B. (2011). The Role of Chalcones in Suppression of NF-KB-Mediated Inflammation and Cancer. $\begin{array}{llll}\text { International } & \text { Immunopharmacology, } & 11 & \text { (3), 295-309. }\end{array}$ https://doi.org/10.1016/j.intimp.2010.12.006

Yoon, Hyungeun, \& Liu, Hai, Rui. (2007). Effect of Selected Phytochemicals and Apple Extracts on NF-KB Activation in Human Breast Cancer MCF-7 Cells. Journal of Agricultural and Food Chemistry 55 (8), 3167-3173. https://doi.org/10.1021/jf0632379

Zhang, Lei., Shi, Lei., Soars, Shafer, Myers., Kamps, Joshua., \& Yin, Hang. (2018). Discovery of Novel Small-Molecule Inhibitors of NF-KB Signaling with Antiinflammatory and Anticancer Properties. Research-article. Journal of Medicinal Chemistry 61 (14), 5881-5899. https://doi.org/10.1021/acs.jmedchem.7b01557 